\title{
The Interplay of the Unfolded Protein Response in Neurodegenerative Diseases: A Therapeutic Role of Curcumin
}

\author{
Sitabja Mukherjee ${ }^{1 t}$, Awdhesh Kumar Mishra ${ }^{2 t}$, G. D. Ghouse Peer ${ }^{3 \dagger}$, \\ Sali Abubaker Bagabir ${ }^{4}$, Shafiul Haque ${ }^{5,6}$, Ramendra Pati Pandey³, V. Samuel Raj ${ }^{3}$, \\ Neeraj Jain ${ }^{7}$, Atul Pandey ${ }^{8,9 *}$ and Santosh Kumar Kar ${ }^{10 *}$ \\ ${ }^{1}$ School of Biotechnology, KIIT University, Bhubaneswar, India, ${ }^{2}$ Department of Biotechnology, Yeungnam University, \\ Gyeongsan, South Korea, ${ }^{3}$ Department of Biotechnology, Sri Ramaswamy Memorial (SRM) University, Sonepat, India, \\ ${ }^{4}$ Department of Medical Laboratory Technology, Faculty of Applied Medical Sciences, Jazan University, Jazan, Saudi Arabia, \\ ${ }^{5}$ Research and Scientific Studies Unit, College of Nursing and Allied Health Sciences, Jazan University, Jazan, Saudi Arabia, \\ ${ }^{6}$ Faculty of Medicine, Bursa Uludağ University, Bursa, Turkey, ${ }^{7}$ Division of Cancer Biology, Council of Scientific and Industrial \\ Research (CSIR)-Central Drug Research Institute, Lucknow, India, ${ }^{8}$ Department of Ecology and Evolutionary Biology, \\ University of Michigan, Ann Arbor, MI, United States, ${ }^{9}$ Department of Ecology, Evolution and Behavior, The Alexander \\ Silberman Institute of Life Science, The Hebrew University of Jerusalem, Jerusalem, Israel, ${ }^{10}$ Nano Herb Research \\ Laboratory, Kalinga Institute of Industrial Technology (KIIT) Technology Business Incubator, KIIT University, Bhubaneswar, \\ India
}

OPEN ACCESS

Edited by:

Rinki Minakshi,

University of Delhi, India

Reviewed by:

Niraj Kumar Jha,

Sharda University, India

Upendra Kumar Singh,

La Jolla Institute for Immunology (LJI),

United States

${ }^{*}$ Correspondence:

Atul Pandey

atulkp@umich.edu

Santosh Kumar Kar

santoshkariis@rediffmail.com

tThese authors have contributed equally to this work and share first authorship

Received: 30 August 2021 Accepted: 18 October 2021 Published: 19 November 2021

Citation:

Mukherjee S, Mishra AK, Peer GDG, Bagabir SA, Haque S, Pandey RP, Raj VS, Jain N, Pandey A and Kar SK (2021) The Interplay of the Unfolded Protein Response in Neurodegenerative Diseases: A Therapeutic Role of Curcumin Front. Aging Neurosci. 13:767493. doi: 10.3389/fnagi.2021.767493
Abnormal accumulation of misfolded proteins in the endoplasmic reticulum and their aggregation causes inflammation and endoplasmic reticulum stress. This promotes accumulation of toxic proteins in the body tissues especially brain leading to manifestation of neurodegenerative diseases. The studies suggest that deregulation of proteostasis, particularly aberrant unfolded protein response (UPR) signaling, may be a common morbific process in the development of neurodegeneration. Curcumin, the mixture of low molecular weight polyphenolic compounds from turmeric, Curcuma longa has shown promising response to prevents many diseases including current global severe acute respiratory syndrome coronavirus 2 (SARS-CoV2) infection and neurodegenerative disorders. The UPR which correlates positively with neurodegenerative disorders were found affected by curcumin. In this review, we examine the evidence from many model systems illustrating how curcumin interacts with UPR and slows down the development of various neurodegenerative disorders (ND), e.g., Alzheimer's and Parkinson's diseases. The recent global increase in ND patients indicates that researchers and practitioners will need to develop a new pharmacological drug or treatment to manage and cure these neurodegenerative diseases.

\footnotetext{
Keywords: Alzheimer's disease, Parkinson's disease, neurodegenaration, unfolded protein response, ER stress, curcumin, ROS-reactive oxygen species, cell death
}

\section{INTRODUCTION}

The global burden of neurological diseases are rising, and considered as one of the leading causes of mortality and disability across the globe (Gammon, 2014; Feigin et al., 2019). The correct folding and packaging of the proteins are essential in regulation of many neurological diseases. All proteins bound to organelles and extracellular spaces are subject to proteostasis (Wang and Kaufman, 2016). 
The abundance of too many secretory proteins in the endoplasmic reticulum (ER) induces the unfolded protein response (UPR) and in case of chronic ER-stress this leads to apoptotic cell death (Taniguchi and Yoshida, 2011; Hetz et al., 2013; Shah et al., 2015; Figure 1). Thus, the UPR protects cells against deformed proteins and maintains cellular homeostasis (Smith and Mallucci, 2016). There are three signal transducers inside the ER, which are inositol requiring enzymes 1 (IRE1) $\alpha$ and $\beta$, protein kinase R-like ER kinase (PERK) categorized as type I, and activating transcription factor 6 (ATF6), $\alpha$ and $\beta$ as type II (Shah et al., 2015; Hetz and Papa, 2018). Various transcription factors activate these signal transducers to restore proteostasis and enhance ER and Golgi biogenesis (Hetz et al., 2020). Neurodegenerative diseases (NDs) are characterized by the degeneration and death of neurons (Pohl et al., 2018). While, the misfolded proteins cause ER-stress-induced neuronal apoptosis in progressive neurodegenerative diseases like Alzheimer's disease (AD), Parkinson's disease (PD) (Hetz and Mollereau, 2014; Scheper and Hoozemans, 2015; Figure 1). AD which accounts for $60-80 \%$ and other forms of dementia are the world's fifth leading cause of death, and its prevalence is expected to triple by 2050, according to WHO (Voulgaropoulou et al., 2019). While, $\mathrm{PD}$ is the most common neurodegenerative disease (20-30\%) after Alzheimer's, with a prevalence of 150/100,000 (Schapira, 1999).
Curcumin, a primary natural polyphenol derived from Curcuma longa rhizome is found affecting a number of diseases including current SARS-CoV-2 infection (Gupta et al., 2013; Noorafshan and Ashkani-Esfahani, 2013; Marton et al., 2020; Sharifi-Rad et al., 2020; Ahmadi et al., 2021). The antioxidant, anti-inflammatory, anti-mutagenic, antiparasitic, antimicrobial and anti-cancerous properties of curcumin are quite explored (Reddy et al., 2005; Aggarwal and Harikumar, 2009; Gupta et al., 2013; Vera-Ramirez et al., 2013; Lestari and Indrayanto, 2014; Hewlings and Kalman, 2017). Recently curcumin was characterized as a pharmacophore by X-ray micro-crystallography of fiber-forming tau fragments with small molecule binders, binding to the $\beta$-pleated layer in tau's paired helical filaments (Landau et al., 2011). Reports suggest that curcumin further scavenges the toxic reactive oxygen species (ROS) and increases Superoxide dismutase (SOD), $\mathrm{Na}^{+}-\mathrm{K}^{+}$ATPase, catalase, glutathione, and mitochondrial complex enzyme levels (Reeta et al., 2010; Barzegar and Moosavi-Movahedi, 2011; Li et al., 2020). It also reduces lipid peroxidation by reducing Malondialdehyde, nitrite, and acetylcholinesterase (Abdel-Diam et al., 2019; Kheirouri and Alizadeh, 2019). Curcumin affects neurogenesis in brain regions involving the Canonical Wnt/-Catenin Pathway (Tiwari et al., 2014). It activates nuclear factor erythroid 2-related factor (Nrf2), the antioxidant master regulator, to protect dopaminergic

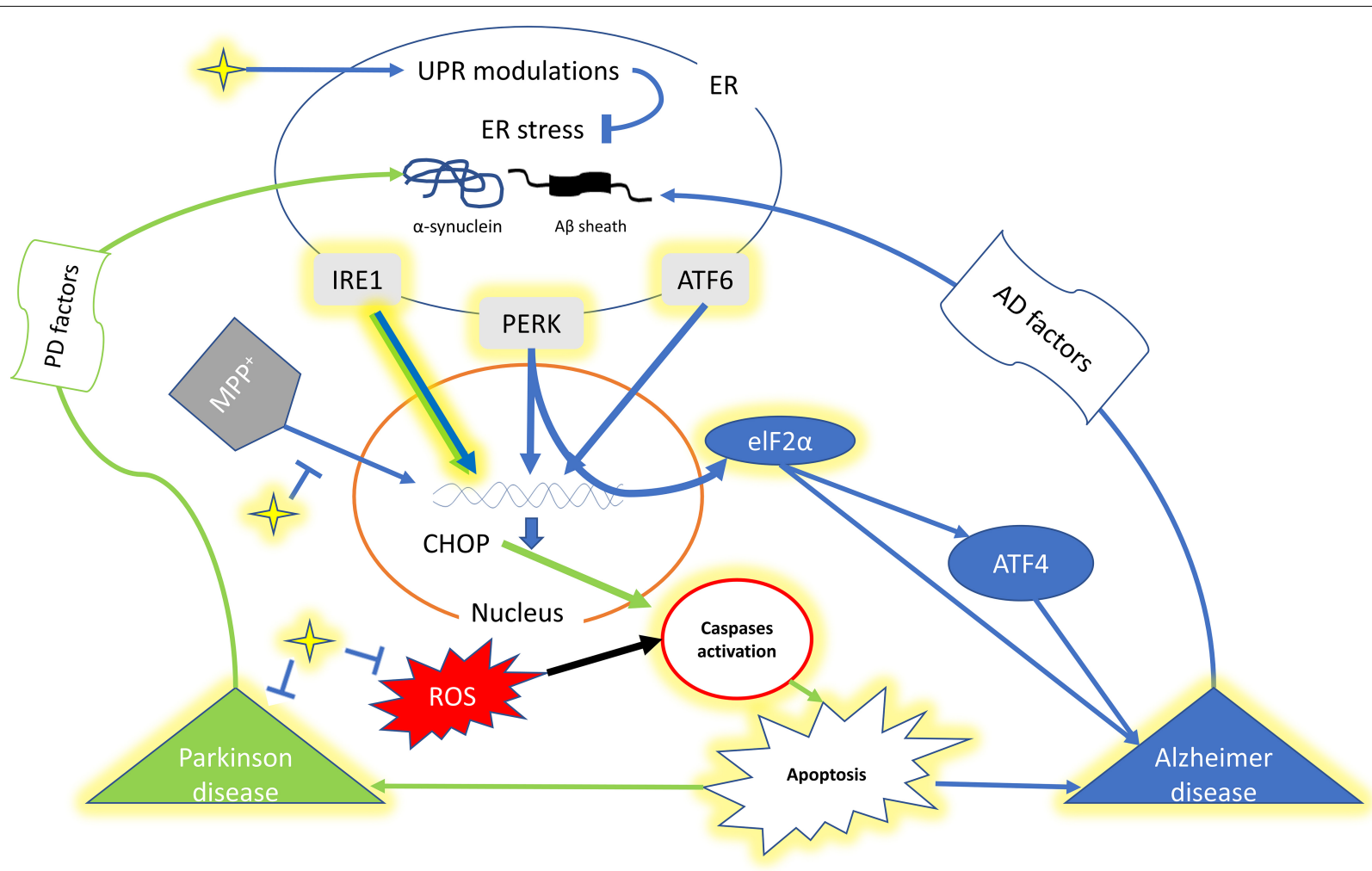

FIGURE 1 | A schematic representation of interplay of curcumin, UPR and factors of Alzheimer's disease and Parkinson's disease. The yellow highlighted genes, component and pathway represents the effect of Curcumin. The star shape (yellow) denotes curcumin. Green arrow shows signaling pathway for PD while Blue of AD. ER, endoplasmic reticulum; IRE1, inositol requiring enzymes 1; PERK, protein kinase R-like ER kinase; ATF4, Activating transcription factor 4; ATF6, Activating transcription factor 6; CHOP, C/EBP Homologous Protein; elF2a, Eukaryotic translation initiation factor 2 alpha. 
neurons (Dong et al., 2018). Furthermore, curcumin increases the expression of $\beta$-tubulin, neuroD1, doublecortin, neurogenic, neuroligin, and neuregulin while decreases the expression of the signal transducer and activator of transcription 3 (STAT3) (Karlstetter et al., 2011). Curcumin further helps in inhibition of neuroinflammation possibly by binding to the sensile plaques, inhibiting $\mathrm{A} \beta$ plaque aggregation, plaque pathology, and decreasing amyloid levels (Lim et al., 2001; McClure et al., 2017; Mei et al., 2020). It also inhibits several dysregulated cellsignaling pathways (Su et al., 2020; Ege, 2021). Curcumin also safeguards against AD (Desai and Patravale, 2018; Nebrisi et al., 2020). Recently, curcumin and curcuminoids were reported as a promising candidate against NDs (Gregory et al., 2021; Ryskalin et al., 2021; Silvestro et al., 2021; Simeonova et al., 2021). Here we review the curcumin's potential role in NDs and UPR regulations. Given the volume of literature, we chosen to focus on with common NDs like AD and PD in relation to UPR.

\section{UNFOLDED PROTEIN RESPONSE AND NEURODEGENERATIVE DISEASES: A COMMON CONNECTION AND CONSEQUENCES}

UPR activation has been observed in many NDs (Scheper and Hoozemans, 2015). Activated astrogliosis, brain aggravation, and microglial multiplication cause ADs (Haass and Selkoe, 2007). The amyloid- $\beta$ (A $\beta)$ peptide aggregates in specific brain areas like the neocortex, hippocampus, and limbic region which further causes synaptic failure and neuronal death (Chyung et al., 2005). UPR is a cellular stress reaction caused by misfolded proteins in the ER, while misfolded proteins accumulate in PD (Taylor et al., 2002). Thus, the UPR is linked to PD in cell models (Hoozemans et al., 2007). In PD, Lewy bodies and protein incorporation in neurites were increased (Mahul-Mellier et al., 2020). Synuclein, a small presynaptic protein, is a major component of Lewy bodies (Clayton and George, 1999; Breydo et al., 2012). The PD patients were also found correlated with higher levels of pPERK, peIF2, and pIRE1 than non-neurological controls (Hoozemans et al., 2007). pPERK-positive neurons had increased diffuse cytoplasmic synuclein immunoreactivity. These findings suggest a link between synuclein accumulation and ER stress in dopaminergic neurons. Further, heat shock reactions and ER or mitochondrial unfolded protein reactions are examples of misfold UPR (Lee et al., 2011; Kakkar et al., 2014; Chiti and Dobson, 2017; Shamsi et al., 2017). By upregulating atomic chaperones and proteasome components, the authors reported the increase in the ability to unfold and refold misfolded proteins, as well as eliminate misfolded proteins (Ciechanover and Kwon, 2017).

\section{CURCUMIN AND NEURODEGENERATIVE DISEASES: INTERVENTIONS AND MODALITIES}

This section reviews curcumin's use and effects on NDs, while focusing on PD and AD. Curcumin's neurological effects make it one of the most promising natural therapies for $\mathrm{AD}$ (Noorafshan and Ashkani-Esfahani, 2013; Eghbaliferiz et al., 2020). The lower prevalence of $\mathrm{AD}$ in India among adults aged 70-79 years (4.4 times lower than in the US) is attributed to higher curcumin use (Ganguli et al., 2000; Yang et al., 2005). Curcumin's ability to bind to $\mathrm{A} \beta$-pleated structure reduces plaque stress in most $\mathrm{AD}$ plaque pathogenesis models (Yang et al., 2005; Garcia-Alloza et al., 2007; Cheng et al., 2013). Curcumin is also known for directly binding and inhibiting the aggregation of $\mathrm{A} \beta$-sheet conformations found in many NDs (Cole et al., 2007; Mishra and Palanivelu, 2008; Forouzanfar et al., 2020; Radbakhsh et al., 2021).

Curcumin inhibits tau aggregation by binding to neurofibrillary tangles (Brunden et al., 2010; Mohorko et al., 2010; Mutsuga et al., 2012). Several $\beta$-pleated layer complexes, such as huntingtin, prion aggregates and $\alpha$-synuclein, are found interacting with curcumin (Caughey et al., 2003; Ono et al., 2004; Pandey et al., 2008). Curcumin interacts directly with heat shock proteins (HSPs), such as HSP90 and HSP70, in A $\beta$-infused rats, tau transgenic mice and human models (Ma et al., 2013). It affects phagocytic cell association with plaque structures and stimulates clearance of $\mathrm{A} \beta$ aggregates in human cell lines and rodent $\mathrm{AD}$ models, similar to the amyloid vaccine (Frautschy et al., 2001; Cole et al., 2004). Curcumin also inhibits NF-к $B$ and Activator Protein 1 (AP1). A dysfunctional transcription factor pathway limits the resolution of inflammation in AD. Curcumin's inhibition of AP1 transcription results in hyperphosphorylation of tau (Singh and Aggarwal, 1995; Xu et al., 1997; Cho et al., 2007). According to recent research, curcumin seems to decrease peroxisome proliferator activated receptor (PPAR) activation by inhibiting Toll-like receptor 4 complex homodimerization. Wang et al. (2010) report that curcumin directly increases PPAR expression. The PPAR forms heterodimers with Retinoid X receptor alpha to control microglial activation and phagocytosis (Heneka et al., 2005). PPAR inhibits pro-inflammatory cytokines that promote tau kinase hyperactivity, pTau buildup, and oxidative damage. Curcumin also promotes oligodendrocyte progenitor (OP) differentiation and inhibits tumor necrosis factor-induced OP maturation arrest through PPAR (Bernardo et al., 2021). Curcumin directly inhibits $\beta$-site amyloid precursor protein-cleaving enzyme 1 (BACE1), which catalyzes the $\mathrm{N}$ terminal cleavage of transmembrane amyloid precursor protein (APP) (Lin et al., 2008), which further indirectly inhibits BACE1 (Huang et al., 2020). Curcumin also reduce A $\beta$ levels by delaying APP maturation in the secretory route (Zhang et al., 2010). The anti-inflammatory properties of curcumin have been linked to improved learning and memory in ApoE4 mice (Kou et al., 2021).

Curcumin combats $\mathrm{AD}$ in various ways, according to recent research (Serafini et al., 2017; Su et al., 2020). It inhibits the production of $\beta$-amyloid, tau, and acetylcholinesterase, controls microglia, and chelates metals (Tang et al., 2017; Voulgaropoulou et al., 2019). Curcumin binds to $A \beta$ and inhibits harmful aggregate formation (Ono et al., 2004; Kim et al., 2005; Yang et al., 2005). However, the diketone bridge in curcumin is not necessary for curcumin's anti-inflammatory actions, since reduced curcumin (tetrahydro curcumin) has strong antiinflammatory characteristics (Begum et al., 2008). By deactivating Glycogen synthase kinase 3 (GSK-3), it reduced A $\beta$ generation 
and plaque formation by downregulating the ROS/JNK pathway. Curcumins inhibition of BACE1 by GSK3 resulted in reduction of $A \beta$ plaques (Durairajan et al., 2012). The precise means by which curcumin regulates these processes are unknown. It seems like that curcumin is a potential antioxidant for treating $\mathrm{AD}$, and that combining carriers and targeting agents to enhance brain delivery is highly effective. In future, more research on curcumin's mechanism of action related to NDs are required.

\section{INTERPLAY OF CURCUMIN AND UNFOLDED PROTEIN RESPONSE}

The ER has vital cellular functions including protein folding, post-translational modification, protein translocation, lipid synthesis, and $\mathrm{Ca}^{2+}$ storage (Schwarz and Blower, 2016). Under ER-stress, evolutionarily conserved UPR response system corrects ER homeostasis by activating transcription factors (ATF4, ATF6, and XBP1) that inhibit protein translation, and promotes unfolded protein destruction (Zhao and Ackerman, 2006; Limonta et al., 2019). In cases of persistent ER stress, the UPR initiates intrinsic apoptotic pathway and cell death (Sano and Reed, 2013). UPR may also be triggered by nonER stress associated mechanisms (Hetz et al., 2020). For example, vascular endothelial growth factor signaling promotes angiogenesis through the UPR pathway (Urra and Hetz, 2014). Considering the vastness of this topic, we have chosen to concentrate on curcumin's role in UPR regulation in NDs.

\section{Curcumin as a Suppressor or Inducer of Unfolded Protein Response in Neurological Diseases \\ Curcumin Function in Brain Injury}

Diffuse axonal injury (DAI) associated with abnormally expressed $\beta$-APP and p-tau proteins in neurons leds to ER-stress induced cell death. Curcumin treatment in rat DAI model increased PERK phosphorylation and decreased CHOP expression and therefore prevented aberrant protein accumulation and inhibited UPR pathway activation (Huang et al., 2018). In another study, curcumin protected against glutamate-induced hippocampus neurotoxicity. The therapeutic role of curcumin against various human diseases are well explored (Shakeri et al., 2019).

\section{Mutation Associated Neuropathies}

Besides having a protective impact on brain injuries, curcumin treatment has also improved peripheral neuropathies. For example, Trembler-J is caused by accumulation of mutated myelin proteins (PMP22) that led to ER stress, UPR activation, and Schwann cell death, which were minimized by curcumin treatment (Okamoto et al., 2013). The second most prevalent autosomal dominant hereditary demyelinating neuropathy is Charcot-Marie-Tooth disease type 1B (CMT1B), caused by activation of UPR components coupled with accumulation of mutant protein myelin protein Zero ( $\mathrm{P} 0, \mathrm{MPZ})$, as a consequence of ER stress (Santoro et al., 2004; Khajavi et al., 2005; Saporta et al., 2011). Using the CMT1B mouse model of human neuropathy, researchers discovered that these mice exhibited motor impairment and axonal abnormalities linked with aberrant UPR activation (Patzkó et al., 2012). It was noted that curcumin formulation could influence the treatment outcomes. Oral curcumin in sesame oil enhanced neurophysiological state and Schwann cell myelination in CMT1B mouse model with decreased UPR signaling (Patzkó et al., 2012). Using the HT22 mouse hippocampus cell line, Chhunchha et al. (2013) discovered that curcumin has anti-oxidative and anti-ER stress properties. Curcumin therapy increased peroxiredoxin 6 (Prdx6) expressions and decreased ER stress in hypoxic HT22 cells (Chhunchha et al., 2013). ApoE4 is the major genetic risk factor for AD associated with dementia. Kou et al. (2021) found that ApoE4 transgenic mice had impaired cognitive capacity, which is linked to ER stress and activation of inflammatory signaling in the nervous system; these were reversed by curcumin treatment in $\mathrm{AD}$ mice. Curcumin is also found effective in Pelizaeus-Merzbacher disease of mice model (Gow et al., 1998; Hübner et al., 2005; Yu et al., 2012).

\section{Analogs of Curcumin and Unfolded Protein Response in Neurological Diseases}

The low bioavailability of curcumin leads to its poor absorption, requiring large doses of curcumin to reach a definite level in plasma. Curcumin plasma levels have been improved by dissolving it in various solutions, coating it with nanoparticles, forming emulsions and by creating its analogs (Sasaki et al., 2011; Zhongfa et al., 2012; Ramalingam and Ko, 2015). There are multiple curcumin analogs have been generated those presented profound effect in modulating ER stress in various cancers model including ovarian, colon, lung, prostrate, gastric, acute promyelocytic leukemia, glioblastoma, melanoma, and triple negative breast cancer cells (Zhang et al., 2012; Qu et al., 2013; Tan et al., 2014; Yoon et al., 2014; Zheng et al., 2014; Chen et al., 2016; Gao et al., 2017; He et al., 2021). However, curcumin mimics' effects on neurodegenerative disorders are poorly documented.

Treatment with CNB-001, a curcumin derivative, reduced intracellular soluble-amyloid build up in $\mathrm{AD}$ transgenic mice by activating the UPR's eIF2/ATF4 signaling (Valera et al., 2013). Protein disulfide isomerase (PDI) is an ER-resident chaperone that is modified to S-nitroso-PDI in the presence of high levels of nitric oxide (NO), which disrupts PDI's redox activity and resulted in the accumulation of misfolded in AD and PD model (Uehara et al., 2006). Curcumin analog 3,5bis (2-flurobenzylidene) piperidin-4-one (EF-24) pretreatment of neuroblastoma cell line SHSY-5Y cells prevented rotenoneinduced (a mitochondrial reactive oxygen species elevator) reduction in PDI expression and ER stress associated protein aggregation (Pal et al., 2011). Glioblastoma is the most common, highly invasive and malignant form of brain cancer currently treated with surgery, radiotherapy and chemotherapy. In a study published by Sansalone et al. (2019) have generated 19 curcumin analogs, out of which 4 have induced glioma stem cells (GSC) death and prevented neurosphere formation. Mechanistically, curcumin analog robustly induced UPR signaling as detected by 
TABLE 1 | Curcumin and its analogs are associated with UPR modulation in neurological disorders.

\begin{tabular}{|c|c|c|c|}
\hline Compound & Disease type/cell line & $\begin{array}{l}\text { Effects on ER stress markers and UPR } \\
\text { signaling }\end{array}$ & References \\
\hline Curcumin & DAI model of rat & $\uparrow(\mathrm{Nrf2}, \mathrm{p}-\mathrm{PERK}), \downarrow(\mathrm{CHOP})$ & Huang et al., 2018 \\
\hline Curcumin & Hippocampus or SH-SY5Y cells & $\begin{array}{l}\uparrow(A M P K), \downarrow(p-I R E 1 \alpha, p-P E R K, N L R P 3, \\
\text { TXNIP/NLRP3) }\end{array}$ & Li et al., 2015 \\
\hline Curcumin & Mouse hippocampus cell HT22 & $\uparrow \operatorname{Prdx6}, \mathrm{CHOP}, \mathrm{Grp} 78), \downarrow(\mathrm{ROS})$ & Valera et al., 2013 \\
\hline Curcumin & Pmp22 Trembler-J mice & $\downarrow($ Atf3 and Ero1-1 $\beta)$ & Okamoto et al., 2013 \\
\hline $\begin{array}{l}\text { Curcumin dissolved in sesame oil or } \\
\text { phosphatidylcholine }\end{array}$ & MPZ ${ }^{R 98 C}$ knock-in mice & $\begin{array}{l}\downarrow \text { (Bip, ATF6, spliced XBP1), no change in } \\
\text { CHOP expression }\end{array}$ & Patzkó et al., 2012 \\
\hline Curcumin & $\begin{array}{l}\text { ApoE4 transgenic mice } \\
\text { (SCXK2016-0004) }\end{array}$ & $\downarrow(\mathrm{NFk} \beta$, APoE4, Grp78, IRE1 $\alpha)$ & Kou et al., 2021 \\
\hline Curcumin & $\begin{array}{l}\text { Transgenic myelin synthesis deficient } \\
\text { model }\end{array}$ & $\begin{array}{l}\text { No changes in expression of Grp78, CHOP, } \\
\text { Gadd45a, calnexin, calreticulin, Herpud1 }\end{array}$ & Yu et al., 2012 \\
\hline CNB-001 (Curcumin analog) & $\begin{array}{l}\text { huAPPswe/PS1E9 transgenic mice and } \\
\text { MC65 cells }\end{array}$ & $\begin{array}{l}\uparrow(p-P E R K, \text { elF2 } \alpha, \text { HSP90, ATF4), } \downarrow \text { (5-LOX, } \\
\beta \text {-amyloid) }\end{array}$ & Valera et al., 2013 \\
\hline EF-24 (Curcumin analog) & SHSY-5Y & $\begin{array}{l}\uparrow(\mathrm{PDI} \text { expression), } \downarrow \text { (AD associated protein } \\
\text { aggregation) }\end{array}$ & Pal et al., 2011 \\
\hline Bis-chalcone 4j (Curcumin analog) & $\begin{array}{l}\text { GSC lines Glio3, Glio4, Glio9, Glio11 } \\
\text { and Glio14 }\end{array}$ & $\uparrow(\mathrm{CHOP}, \mathrm{p}$-jun and caspase 12) & Sansalone et al., 2019 \\
\hline C-150 (Curcumin analog) & $\begin{array}{l}\text { GBM1-6, U87 MG, U251 MG and } \\
\text { U373 MG }\end{array}$ & $\begin{array}{l}\uparrow(\text { Grp78, GADD153, ATF4, XBP1), } \downarrow \text { (NFk } \beta \text {, } \\
\text { Akt, PKC } \alpha \text { kinase activity) }\end{array}$ & Hackler et al., 2016 \\
\hline
\end{tabular}

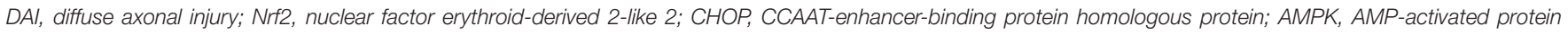

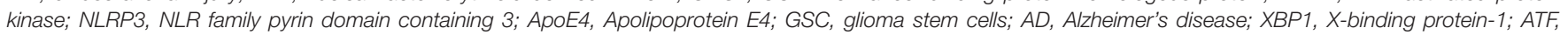

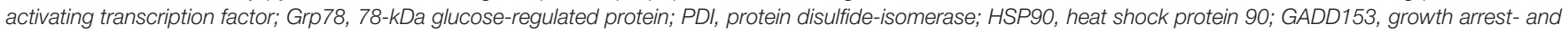

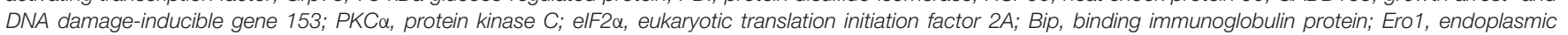
oxidoreductin-1; Prdx6, peroxiredoxin-6; ROS, reactive oxygen species.

increased expression of CHOP, p-jun and caspase 12 markers (Sansalone et al., 2019). Another study by Hackler et al. (2016) has demonstrated the cytotoxic effect of curcumin derivative C-150 (Mannich-type) on eight glioma cell lines. C-150 treatment in gliomas cells significantly affected expression of UPR proteins, Akt, and PKC $\alpha$ activity.

Overall, curcumin and its derivatives are neuroprotective in various neurological disorders and kill cancer cells via modulating UPR signaling (Table 1). The main difficulty is to formulate curcumin or its counterpart in the correct dosage and administer it in a proper manner. This includes undoubtedly to overcome poor absorption, rapid metabolism and poor bioavailability of curcumin and substantially improve its beneficial activities.

\section{CURCUMIN, UNFOLDED PROTEIN RESPONSE AND NEURODEGENERATIVE DISEASES: A TRIVIAL CONNECTION AND FUTURE PERSPECTIVES}

The studies suggest that deregulation of proteostasis, particularly aberrant UPR signaling, may be a common pathogenic mechanism in the development of ND. While modulation of the UPR in animal illness models, including $\mathrm{AD}$, has shown early promises. To determine whether UPR signaling is a protective mechanism or actively contributes to disease development, neuropathological data alone cannot be used. The idea of targeting the UPR, and specifically the PERK signaling is extremely interesting (Das et al., 2015). Some protein misfolding in NDs appear to benefit from selectively increasing protein synthesis upstream or downstream of eIF2a-P to avoid pancreatic toxicity associated with systemic PERK inhibition.

Researchers also discovering novel UPR activation methods, e.g., mitochondria-associated ER membranes are gaining popularity as a possible therapeutic target in NDs. Disrupted connections between the ER and mitochondria have been identified were curcumin seems to influence ER-mitochondrial interactions (Paillusson et al., 2016). Curcumin as licensed drug delaying the development of dementia in different model systems, this is an intriguing idea and a major step forward in the quest for a therapeutic agent for neurodegeneration. The next issue will be identifying how best and when to regulate the PERK pathway in patients, given that there are many proven therapeutic targets along the route. What remains unclear if curcumin may directly interfere in neurodegeneration without engaging UPR components?

Curcumin affect the action of many factors such as NF- $\mathrm{B}$ and AP-1 (Han et al., 2002). Curcumin binds to different proteins and enzymes and modulate their conformation and biological activities. Curcumin's linker length and flexibility make it ideal for binding to $A \beta$ aggregates. Curcumin's unique structure, which consists of an, $\alpha, \beta$-unsaturated $\beta$-diketone moiety linked by a seven carbon heptadiene chain, allows it to remain in keto-enol tautomeric forms in solution depending on the $\mathrm{pH}$. When the $\mathrm{pH}$ is between 3 and 7 , it is in the keto form, whereas the enol form is found around $\mathrm{pH}$. Curcumin retains its coplanarity 
and extends the double-bond conjugation through six membered hydrogen bonding at the center when it is in the enol form which has strong $A \beta$ aggregate binding activities. Curcumin, on the other hand, has very low binding activities for $A \beta$ aggregates when it is in the keto form. Studies have shown that to be able to bind to $A \beta$ aggregates, compounds need to be coplanar and have a double-bond conjugation of certain length. Curcumin, however, has certain disadvantages too, which includes its low water solubility and bioavailability. Dissolving it into organic solvent improves it solubility but its absorption remains poor (Ege, 2021; Jia et al., 2021). Some recent articles addressed the methods to enhance curcumin's effectiveness in treating AD (Fan et al., 2018; Francesco et al., 2019; Ege, 2021). In future curcumin compounds must be chemically screened on target enzymes and proteins to facilitate more information.

Overall, the studies suggest that curcumin may prevents or postpones the onset of NDs by decreasing ER stress which seems to be responsible for NDs through a complicated processes (Figure 1). Additional mechanistic studies are needed to establish curcumin's role in reducing ER stress. Despite promising preclinical findings, there are currently no clinical data to support curcumin as part of a drug therapy against NDs. The recent rise in the number of NDs patients across the globe suggests that researchers and practitioners will need to discover an effective

\section{REFERENCES}

Abdel-Diam, M. M., Samak, D. H., El-Sayed, Y. S., Aleya, L., Alarifi, S., and Alkahtani, S. (2019). Curcumin and quercetin synergistically attenuate subacute diazinon-induced inflammation and oxidative neurohepatic damage, and acetylcholinesterase inhibition in albino rats. Environ. Sci. Pollut. Res. Int. 26, 3659-3665. doi: 10.1007/S11356-018-3907-9

Aggarwal, B. B., and Harikumar, K. B. (2009). Potential therapeutic effects of curcumin, the anti-inflammatory agent, against neurodegenerative, cardiovascular, pulmonary, metabolic, autoimmune and neoplastic diseases. Int. J. Biochem. Cell Biol. 41, 40-59. doi: 10.1016/j.biocel.2008.06.010

Ahmadi, R., Salari, S., Sharifi, M. D., Reihani, H., Rostamiani, M. B., Behmadi, M., et al. (2021). Oral nano-curcumin formulation efficacy in the management of mild to moderate outpatient COVID-19: A randomized triple-blind placebocontrolled clinical trial. Food Sci. Nutr. 9, 4068-4075. doi: 10.1002/FSN3.2226

Barzegar, A., and Moosavi-Movahedi, A. A. (2011). Intracellular ROS protection efficiency and free radical-scavenging activity of curcumin. PLoS One 6:26012. doi: 10.1371 /journal.pone.0026012

Begum, A. N., Jones, M. R., Lim, G. P., Morihara, T., Kim, P., Heath, D. D., et al. (2008). Curcumin structure-function, bioavailability, and efficacy in models of neuroinflammation and Alzheimer's disease. J. Pharmacol. Exp. Ther. 326, 196-208. doi: 10.1124/jpet.108.137455

Bernardo, A., Plumitallo, C., De Nuccio, C., Visentin, S., and Minghetti, L. (2021). Curcumin promotes oligodendrocyte differentiation and their protection against TNF- $\alpha$ through the activation of the nuclear receptor PPAR- $\gamma$. Sci. Rep. 11:4952.

Breydo, L., Wu, J. W., and Uversky, V. N. (2012). A-synuclein misfolding and Parkinson's disease. Biochim. Biophys. Acta 1822, 261-285. doi: 10.1016/J. BBADIS.2011.10.002

Brunden, K. R., Ballatore, C., Crowe, A., Smith, A. B., Lee, V. M. Y., and Trojanowski, J. Q. (2010). Tau-directed drug discovery for Alzheimer's disease and related tauopathies: A focus on tau assembly inhibitors. Exp. Neurol. 223, 304-310. doi: 10.1016/j.expneurol.2009.08.031

Caughey, B., Raymond, L. D., Raymond, G. J., Maxson, L., Silveira, J., and Baron, G. S. (2003). Inhibition of Protease-Resistant Prion Protein Accumulation In Vitro by Curcumin. J. Virol. 77, 5499-5502. doi: 10.1128/jvi.77.9.5499-5502. 2003 pharmaceutical medication or therapy to successfully treat these illnesses in the future. Curcumin's interaction and mechanism of action against NDs warrants a more research to accomplish this goal.

\section{AUTHOR CONTRIBUTIONS}

NJ, RP, AP, and SK contributed to the conception and design of the study. SM, AM, GP, NJ, and AP organized the material and wrote the first draft of the manuscript. SM, GP, SB, SH, NJ, and AP wrote sections of the manuscript. RP, VR, NJ, AP, and SK helped with manuscript editing and formatting. All authors contributed to manuscript revision, read, and approved the submitted version.

\section{FUNDING}

NJ was supported by the Ramalingaswami grant (BT/RLF/Reentry/18/2017) from the Department of Biotechnology, Ministry of Science and Technology, Government of India. AP was supported by the Planning and Budgeting Committee (PBC) outstanding postdoctoral fellowship, Israel.

Chen, W., Zou, P., Zhao, Z., Weng, Q., Chen, X., Ying, S., et al. (2016). Selective killing of gastric cancer cells by a small molecule via targeting TrxR1 and ROS-mediated ER stress activation. Oncotarget 7, 16593-16609. doi: 10.18632/ oncotarget.7565

Cheng, K. K., Yeung, C. F., Ho, S. W., Chow, S. F., Chow, A. H. L., and Baum, L. (2013). Highly stabilized curcumin nanoparticles tested in an in vitro bloodbrain barrier model and in alzheimer's disease Tg2576 Mice. AAPS J. 15, 324-336. doi: 10.1208/s12248-012-9444-4

Chhunchha, B., Fatma, N., Kubo, E., Rai, P., Singh, S. P., and Singh, D. P. (2013). Curcumin abates hypoxia-induced oxidative stress based-ER stress-mediated cell death in mouse hippocampal cells (HT22) by controlling Prdx6 and NF-кB regulation. Am. J. Physiol. Cell Physiol. 304, C636-C655. doi: 10.1152/ajpcell. 00345.2012

Chiti, F., and Dobson, C. (2017). Protein Misfolding amyloid formation, and Human Disease: a summary of progress over the last decade. Annu. Rev. Biochem. 86, 27-68. doi: 10.1146/ANNUREV-BIOCHEM-061516-045115

Cho, J. W., Lee, K. S., and Kim, C. W. (2007). Curcumin attenuates the expression of IL-1 $\beta$, IL- 6 , and TNF- $\alpha$ as well as cyclin E in TNF- $\alpha$-treated HaCaT cells; NF-кB and MAPKs as potential upstream targets. Int. J. Mol. Med. 19, 469-474. doi: 10.3892/ijmm.19.3.469

Chyung, J. H., Raper, D. M., and Selkoe, D. J. (2005). Gamma-secretase exists on the plasma membrane as an intact complex that accepts substrates and effects intramembrane cleavage. J. Biol. Chem. 280, 4383-4392. doi: 10.1074/ jbc.M409272200

Ciechanover, A., and Kwon, Y. (2017). Protein Quality Control by Molecular Chaperones in Neurodegeneration. Front. Neurosci 11:185. doi: 10.3389/ FNINS.2017.00185

Clayton, D. F., and George, J. M. (1999). Synucleins in Synaptic Plasticity and Neurodegenerative Disorders. J. Neurosci. Res 58, 120-129. doi: 10.1002/(SICI) 1097-4547(19991001)58

Cole, G. M., Morihara, T., Lim, G. P., Yang, F., Begum, A., and Frautschy, S. A. (2004). NSAID and antioxidant prevention of Alzheimer's disease: lessons from in vitro and animal models. Ann. N. Y. Acad. Sci. 1035, 68-84. doi: 10.1196/ annals. 1332.005

Cole, G. M., Teter, B., and Frautschy, S. A. (2007). Neuroprotective effects of curcumin. Adv. Exp. Med. Biol. 595, 197-212. doi: 10.1007/978-0-38746401-5_8 
Das, I., Krzyzosiak, A., Schneider, K., Wrabetz, L., D’Antonio, M., Barry, N., et al. (2015). Preventing proteostasis diseases by selective inhibition of a phosphatase regulatory subunit. Science 348, 239-242. doi: 10.1126/science.aaa4484

Desai, P. P., and Patravale, V. B. (2018). Curcumin Cocrystal MicellesMultifunctional Nanocomposites for Management of Neurodegenerative Ailments. J. Pharm. Sci. 107, 1143-1156. doi: 10.1016/j.xphs.2017.11.014

Dong, W., Yang, B., Wang, L., Li, B., Guo, X., Zhang, M., et al. (2018). Curcumin plays neuroprotective roles against traumatic brain injury partly via Nrf2 signaling. Toxicol. Appl. Pharmacol. 346, 28-36. doi: 10.1016/j.taap.2018.03.020

Durairajan, S. S. K., Liu, L.-F., Lu, J.-H., Chen, L.-L., Yuan, Q., Chung, S. K., et al. (2012). Berberine ameliorates $\beta$-amyloid pathology, gliosis, and cognitive impairment in an Alzheimer's disease transgenic mouse model. Neurobiol. Aging 33, 2903-2919. doi: 10.1016/j.neurobiolaging.2012.02.016

Ege, D. (2021). Action Mechanisms of Curcumin in Alzheimer's Disease and Its Brain Targeted Delivery. Mater14:332. doi: 10.3390/MA14123332

Eghbaliferiz, S., Farhadi, F., Barreto, G. E., Majeed, M., and Sahebkar, A. (2020). Effects of curcumin on neurological diseases: focus on astrocytes. Pharmacol. Rep. 72, 769-782. doi: 10.1007/s43440-020-00112-3

Fan, Y., Yi, J., Zhang, Y., and Yokoyama, W. (2018). Fabrication of curcuminloaded bovine serum albumin (BSA)-dextran nanoparticles and the cellular antioxidant activity. Food Chem. 239, 1210-1218. doi: 10.1016/j.foodchem. 2017.07.075

Feigin, V., Emma, N., Tahiya, A., Marlena, S. B., and Gbd 2016 Neurology Collaborators. (2019). Global, regional, and national burden of neurological disorders, 1990-2016: a systematic analysis for the Global Burden of Disease Study 2016. Lancet Neurol. 18, 459-480. doi: 10.1016/S1474-4422(18) 30499-X

Forouzanfar, F., Read, M. I., Barreto, G. E., and Sahebkar, A. (2020). Neuroprotective effects of curcumin through autophagy modulation. IUBMB Life 72, 652-664. doi: 10.1002/iub.2209

Francesco, D. M., Margarucci, S., Galderisi, U., Crispi, S., and Peluso, G. (2019). Curcumin, gut microbiota, and neuroprotection. Nutrients 11:2426. doi: 10 . 3390/nu11102426

Frautschy, S. A., Hu, W., Kim, P., Miller, S. A., Chu, T., Harris-White, M. E., et al. (2001). Phenolic anti-inflammatory antioxidant reversal of A $\beta$-induced cognitive deficits and neuropathology. Neurobiol. Aging 22, 993-1005. doi: 10.1016/S0197-4580(01)00300-1

Gammon, K. (2014). Neurodegenerative disease: brain windfall. Nature 515, 299300. doi: 10.1038/NJ7526-299A

Ganguli, M., Chandra, V., Kamboh, M. I., Johnston, J. M., Dodge, H. H., Thelma, B. K., et al. (2000). Apolipoprotein E polymorphism and Alzheimer disease: The Indo-US Cross-National Dementia Study. Arch. Neurol. 57, 824-830. doi: 10.1001/archneur.57.6.824

Gao, J., Fan, M., Peng, S., Zhang, M., Xiang, G., Li, X., et al. (2017). Small-molecule RL71-triggered excessive autophagic cell death as a potential therapeutic strategy in triple-negative breast cancer. Cell Death Dis. 8:e3049. doi: 10.1038/ cddis. 2017.444

Garcia-Alloza, M., Borrelli, L. A., Rozkalne, A., Hyman, B. T., and Bacskai, B. J. (2007). Curcumin labels amyloid pathology in vivo, disrupts existing plaques, and partially restores distorted neurites in an Alzheimer mouse model. J. Neurochem. 102, 1095-1104. doi: 10.1111/j.1471-4159.2007.04613.x

Gow, A., Southwood, C. M., and Lazzarini, R. A. (1998). Disrupted proteolipid protein trafficking results in oligodendrocyte apoptosis in an animal model of Pelizaeus-Merzbacher disease. J. Cell Biol. 140, 925-934. doi: 10.1083/jcb.140. 4.925

Gregory, J., Vengalasetti, Y. V., Bredesen, D. E., and Rao, R. V. (2021). Neuroprotective herbs for the management of alzheimer's disease. Biomolecules 11:543. doi: 10.3390/biom 11040543

Gupta, S. C., Patchva, S., and Aggarwal, B. B. (2013). Therapeutic roles of curcumin: Lessons learned from clinical trials. AAPS J. 15, 195-218. doi: 10.1208/s12248012-9432-8

Haass, C., and Selkoe, D. (2007). Soluble protein oligomers in neurodegeneration: lessons from the Alzheimer's amyloid beta-peptide. Nat. Rev. Mol. Cell Biol. 8, 101-112. doi: 10.1038/NRM2101

Hackler, L., Ózsvári, B., Gyuris, M., Sipos, P., Fábián, G., Molnár, E., et al. (2016). The Curcumin Analog C-150, Influencing NF- $\kappa B$, UPR and Akt/Notch Pathways Has Potent Anticancer Activity In Vitro and In Vivo. PLoS One 11:e0149832. doi: 10.1371/journal.pone.0149832
Han, S.-S., Keum, Y.-S., Seo, H.-J., and Surh, Y.-J. (2002). Curcumin Suppresses Activation of NF- $\kappa$ B and AP-1 Induced by Phorbol Ester in Cultured Human Promyelocytic Leukemia Cells. J. Biochem. Mol. Biol. 35, 337-342.

He, Y., Li, W., Zhang, J., Yang, Y., Qian, Y.-W., and Zhou, D. (2021). The curcumin analog EF24 is highly active against chemotherapy-resistant melanoma cells. Curr. Cancer Drug Targets 21, 608-618. doi: 10.2174/ 1568009621666210303092921

Heneka, M. T., Sastre, M., Dumitrescu-Ozimek, L., Hanke, A., Dewachter, I., Kuiperi, C., et al. (2005). Acute treatment with the PPARgamma agonist pioglitazone and ibuprofen reduces glial inflammation and Abeta1-42 levels in APPV717I transgenic mice. Brain 128, 1442-1453. doi: 10.1093/brain/ awh452

Hetz, C., Chevet, E., and Harding, H. P. (2013). Targeting the unfolded protein response in disease. Nat. Rev. Drug Discov. 129, 703-719. doi: 10.1038/nrd 3976

Hetz, C., and Mollereau, B. (2014). Disturbance of endoplasmic reticulum proteostasis in neurodegenerative diseases. Nat. Rev. Neurosci. 15, 233-249. doi: $10.1038 /$ NRN3689

Hetz, C., and Papa, F. (2018). The Unfolded Protein Response and Cell Fate Control. Mol. Cell 69, 169-181. doi: 10.1016/J.MOLCEL.2017.06.017

Hetz, C., Zhang, K., and Kaufman, R. J. (2020). Mechanisms, regulation and functions of the unfolded protein response. Nat. Rev. Mol. Cell Biol. 21, 421-438. doi: 10.1038/s41580-020-0250-z

Hewlings, S., and Kalman, D. (2017). Curcumin: A Review of Its Effects on Human Health. Foods 6:92. doi: 10.3390/FOODS6100092

Hoozemans, J. J. M., van Haastert, E. S., Eikelenboom, P., de Vos, R. A. I., Rozemuller, J. M., and Scheper, W. (2007). Activation of the unfolded protein response in Parkinson's disease. Biochem. Biophys. Res. Commun. 354, 707-711. doi: 10.1016/j.bbrc.2007.01.043

Huang, P., Zheng, N., Zhou, H.-B., and Huang, J. (2020). Curcumin inhibits BACE1 expression through the interaction between $\mathrm{ER} \beta$ and NFKB signaling pathway in SH-SY5Y cells. Mol. Cell. Biochem. 463, 161-173. doi: 10.1007/s11010-01903638-0

Huang, T., Zhao, J., Guo, D., Pang, H., Zhao, Y., and Song, J. (2018). Curcumin mitigates axonal injury and neuronal cell apoptosis through the PERK/Nrf2 signaling pathway following diffuse axonal injury. Neuroreport 29, 661-677. doi: 10.1097/WNR.0000000000001015

Hübner, C. A., Orth, U., Senning, A., Steglich, C., Kohlschütter, A., Korinthenberg, R., et al. (2005). Seventeen novel PLP1 mutations in patients with PelizaeusMerzbacher disease. Hum. Mutat. 25, 321-322. doi: 10.1002/humu.9314

Jia, F., Chibhabha, F., Yang, Y., Kuang, Y., Zhang, Q., Ullah, S., et al. (2021). Detection and monitoring of the neuroprotective behavior of curcumin micelles based on an AIEgen probe. J. Mater. Chem. B 9, 731-745. doi: 10.1039/ d0tb02320e

Kakkar, V., Meister-Broekema, M., Minoia, M., Carra, S., and Kampinga, H. H. (2014). Barcoding heat shock proteins to human diseases: looking beyond the heat shock response. Dis. Model. Mech. 7, 421-434. doi: 10.1242/dmm.014563

Karlstetter, M., Lippe, E., Walczak, Y., Moehle, C., Aslanidis, A., Mirza, M., et al. (2011). Curcumin is a potent modulator of microglial gene expression and migration. J. Neuroinfl. 8, 1-12. doi: 10.1186/1742-2094-8-125

Khajavi, M., Inoue, K., Wiszniewski, W., Ohyama, T., Snipes, G. J., and Lupski, J. R. (2005). Curcumin treatment abrogates endoplasmic reticulum retention and aggregation-induced apoptosis associated with neuropathy-causing myelin protein zero-truncating mutants. Am. J. Hum. Genet. 77, 841-850. doi: 10.1086/ 497541

Kheirouri, S., and Alizadeh, M. (2019). Dietary Inflammatory Potential and the Risk of Neurodegenerative Diseases in Adults. Epidemiol. Rev. 41, 109-120. doi: 10.1093/EPIREV/MXZ005

Kim, H., Park, B. S., Lee, K. G., Cheol, Y. C., Sung, S. J., Kim, Y. H., et al. (2005). Effects of naturally occurring compounds on fibril formation and oxidative stress of $\beta$-amyloid. J. Agric. Food Chem. 53, 8537-8541. doi: 10.1021/jf051985c

Kou, J., Wang, M., Shi, J., Zhang, H., Pu, X., Song, S., et al. (2021). Curcumin Reduces Cognitive Deficits by Inhibiting Neuroinflammation through the Endoplasmic Reticulum Stress Pathway in Apolipoprotein E4 Transgenic Mice. ACS Omega 6, 6654-6662. doi: 10.1021/acsomega.0c04810

Landau, M., Sawaya, M. R., Faull, K. F., Laganowsky, A., Jiang, L., Sievers, S. A., et al. (2011). Towards a pharmacophore for amyloid. PLOS Biol. 9:e1001080. doi: 10.1371/journal.pbio.1001080 
Lee, S.-J., Lim, H.-S., Masliah, E., and Lee, H.-J. (2011). Protein aggregate spreading in neurodegenerative diseases: problems and perspectives. Neurosci. Res. 70, 339-348. doi: 10.1016/j.neures.2011.05.008

Lestari, M. L. A. D., and Indrayanto, G. (2014). Curcumin.Profiles Drug Subst. Excip. Relat. Methodol. 39, 113-204. doi: 10.1016/B978-0-12-800173-8.000039

Li, H., Dai, Y., Wu, H., Luo, L., Wei, L., Zhou, L., et al. (2020). Predictors of Early Neurologic Deterioration in Acute Pontine Infarction. Stroke 51, 637-640. doi: 10.1161/STROKEAHA.119.027239

Li, Y., Li, J., Li, S., Li, Y., Wang, X., Liu, B., et al. (2015). Curcumin attenuates glutamate neurotoxicity in the hippocampus by suppression of ER stressassociated TXNIP/NLRP3 inflammasome activation in a manner dependent on AMPK. Toxicol. Appl. Pharmacol. 286, 53-63. doi: 10.1016/j.taap.2015.03.010

Lim, G. P., Chu, T., Yang, F., Beech, W., Frautschy, S. A., and Cole, G. M. (2001). The curry spice curcumin reduces oxidative damage and amyloid pathology in an Alzheimer transgenic mouse. J. Neurosci. 21, 8370-8377. doi: 10.1523/ jneurosci.21-21-08370.2001

Limonta, P., Moretti, R. M., Marzagalli, M., Fontana, F., Raimondi, M., and Montagnani Marelli, M. (2019). Role of Endoplasmic Reticulum Stress in the Anticancer Activity of Natural Compounds. Int. J. Mol. Sci. 20:961. doi: 10.3390/ ijms20040961

Lin, R., Chen, X., Li, W., Han, Y., Liu, P., and Pi, R. (2008). Exposure to metal ions regulates mRNA levels of APP and BACE1 in PC12 cells: Blockage by curcumin. Neurosci. Lett. 440, 344-347. doi: 10.1016/j.neulet.2008.05.070

Ma, Q.-L., Zuo, X., Yang, F., Ubeda, O. J., Gant, D. J., Alaverdyan, M., et al. (2013). Curcumin suppresses soluble tau dimers and corrects molecular chaperone, synaptic, and behavioral deficits in aged human tau transgenic mice. J. Biol. Chem. 288, 4056-4065. doi: 10.1074/jbc.M112.393751

Mahul-Mellier, A.-L., Burtscher, J., Maharjan, N., Weerens, L., Croisier, M., Kuttler, F., et al. (2020). The process of Lewy body formation, rather than simply $\alpha$ synuclein fibrillization, is one of the major drivers of neurodegeneration. Proc. Natl. Acad. Sci. U.S.A. 117, 4971-4982. doi: 10.1073/pnas.1913904117

Marton, L. T., Barbalho, S. M., Sloan, K. P., Sloan, L. A., Goulart, R., de, A., et al. (2020). Curcumin, autoimmune and inflammatory diseases: going beyond conventional therapy - a systematic review. Crit. Rev. Food Sci. Nutr. 1, 1-19. doi: 10.1080/10408398.2020.1850417

McClure, R., Ong, H., Janve, V., Barton, S., Zhu, M., Li, B., et al. (2017). Aerosol Delivery of Curcumin Reduced Amyloid- $\beta$ Deposition and Improved Cognitive Performance in a Transgenic Model of Alzheimer's Disease. J. Alzheimer's Dis. 55, 797-811. doi: 10.3233/JAD- 160289

Mei, X., Zhu, L., Zhou, Q., Li, X., and Chen, Z. (2020). Interplay of curcumin and its liver metabolism on the level of A $\beta$ in the brain of APPswe/PS1dE9 mice before AD onset. Pharmacol. Rep. 72, 1604-1613. doi: 10.1007/s43440-020-00116-z

Mishra, K., and Palanivelu, K. (2008). The effect of curcumin (turmeric) on Alzheimer's disease: An overview. Ann. Indian Acad. Neurol. 11, 13-19. doi: 10.4103/0972-2327.40220

Mohorko, N., Repovs, G., Popović, M., Kovacs, G. G., and Bresjanac, M. (2010). Curcumin labeling of neuronal fibrillar tau inclusions in human brain samples. J. Neuropathol. Exp. Neurol. 69, 405-414. doi: 10.1097/NEN.0b013e3181d709eb

Mutsuga, M., Chambers, J. K., Uchida, K., Tei, M., Makibuchi, T., Mizorogi, T., et al. (2012). Binding of curcumin to senile plaques and cerebral amyloid angiopathy in the aged brain of various animals and to neurofibrillary tangles in Alzheimer's brain. J. Vet. Med. Sci. 74, 51-57. doi: 10.1292/jvms.11-0307

Nebrisi, E., El, Javed, H., Ojha, S. K., Oz, M., and Shehab, S. (2020). Neuroprotective effect of curcumin on the nigrostriatal pathway in a 6-hydroxydopmineinduced rat model of parkinson's disease is mediated by $\alpha 7$-nicotinic receptors. Int. J. Mol. Sci. 21, 1-19. doi: 10.3390/ijms21197329

Noorafshan, A., and Ashkani-Esfahani, S. (2013). A Review of Therapeutic Effects of Curcumin. Curr. Pharm. Des. 19, 2032-2046. doi: 10.2174/ 138161213805289273

Okamoto, Y., Pehlivan, D., Wiszniewski, W., Beck, C. R., Snipes, G. J., Lupski, J. R., et al. (2013). Curcumin facilitates a transitory cellular stress response in Trembler-J mice. Hum. Mol. Genet. 22, 4698-4705. doi: 10.1093/hmg/ddt318

Ono, K., Hasegawa, K., Naiki, H., and Yamada, M. (2004). Curcumin has potent anti-amyloidogenic effects for Alzheimer's beta-amyloid fibrils in vitro. J. Neurosci. Res. 75, 742-750. doi: 10.1002/jnr.20025

Paillusson, S., Stoica, R., Gomez-Suaga, P., Lau, D. H. W., Mueller, S., Miller, T., et al. (2016). There's Something Wrong with my MAM; the ER-Mitochondria
Axis and Neurodegenerative Diseases. Trends Neurosci. 39, 146-157. doi: 10. 1016/j.tins.2016.01.008

Pal, R., Miranda, M., and Narayan, M. (2011). Nitrosative stress-induced Parkinsonian Lewy-like aggregates prevented through polyphenolic phytochemical analog intervention. Biochem. Biophys. Res. Commun. 404, 324-329. doi: 10.1016/j.bbrc.2010.11.117

Pandey, N., Strider, J., Nolan, W. C., Yan, S. X., and Galvin, J. E. (2008). Curcumin inhibits aggregation of $\alpha$-synuclein. Acta Neuropathol. 115, 479-489. doi: 10. 1007/s00401-007-0332-4

Patzkó, A., Bai, Y., Saporta, M. A., Katona, I., Wu, X., Vizzuso, D., et al. (2012). Curcumin derivatives promote Schwann cell differentiation and improve neuropathy in R98C CMT1B mice. Brain 135, 3551-3566. doi: 10.1093/brain/ aws 299

Pohl, F., Kong Thoo, and Lin, P. (2018). The Potential Use of Plant Natural Products and Plant Extracts with Antioxidant Properties for the Prevention/Treatment of Neurodegenerative Diseases: In Vitro, In Vivo and Clinical Trials. Molecules 23:3283. doi: 10.3390/MOLECULES231 23283

Qu, W., Xiao, J., Zhang, H., Chen, Q., Wang, Z., Shi, H., et al. (2013). B19, a novel monocarbonyl analogue of curcumin, induces human ovarian cancer cell apoptosis via activation of endoplasmic reticulum stress and the autophagy signaling pathway. Int. J. Biol. Sci. 9, 766-777. doi: 10.7150/ijbs.5711

Radbakhsh, S., Barreto, G. E., Bland, A. R., and Sahebkar, A. (2021). Curcumin: A small molecule with big functionality against amyloid aggregation in neurodegenerative diseases and type 2 diabetes. Biofactors 47, 570-586. doi: 10.1002/biof.1735

Ramalingam, P., and Ko, Y. (2015). Enhanced oral delivery of curcumin from N-trimethyl chitosan surface-modified solid lipid nanoparticles: pharmacokinetic and brain distribution evaluations. Pharm. Res. 32, 389-402. doi: 10.1007/S11095-014-1469-1

Reddy, R. C., Vatsala, P. G., Keshamouni, V. G., Padmanaban, G., and Rangarajan, P. N. (2005). Curcumin for malaria therapy. Biochem. Biophys. Res. Commun. 326, 472-474. doi: 10.1016/j.bbrc.2004.11.051

Reeta, K. H., Mehla, J., and Gupta, Y. K. (2010). Curcumin ameliorates cognitive dysfunction and oxidative damage in phenobarbitone and carbamazepine administered rats. Eur. J. Pharmacol. 644, 106-112. doi: 10.1016/j.ejphar.2010. 07.022

Ryskalin, L., Puglisi-Allegra, S., Lazzeri, G., Biagioni, F., Busceti, C. L., Balestrini, L., et al. (2021). Neuroprotective effects of curcumin in methamphetamineinduced toxicity. Molecules 26:2493. doi: 10.3390/molecules 26092493

Sano, R., and Reed, J. (2013). ER stress-induced cell death mechanisms. Biochim. Biophys. Acta 1833, 3460-3470. doi: 10.1016/J.BBAMCR.2013.06.028

Sansalone, L., Veliz, E. A., Myrthil, N. G., Stathias, V., Walters, W., Torrens, I. I., et al. (2019). Novel Curcumin Inspired Bis-Chalcone Promotes Endoplasmic Reticulum Stress and Glioblastoma Neurosphere Cell Death. Cancers 11:E357. doi: 10.3390/cancers11030357

Santoro, L., Manganelli, F., Maria, E., Di, Bordo, D., Cassandrini, D., et al. (2004). A novel mutation of myelin protein zero associated with an axonal form of Charcot-Marie-Tooth disease. J. Neurol. Neurosurg. Psychiatry 75, 262-265. doi: 10.1136/JNNP.2003.012278

Saporta, A. S. D., Sottile, S. L., Miller, L. J., Feely, S. M. E., Siskind, C. E., and Shy, M. E. (2011). Charcot-Marie-Tooth disease subtypes and genetic testing strategies. Ann. Neurol. 69, 22-33. doi: 10.1002/ana.22166

Sasaki, H., Sunagawa, Y., Takahashi, K., Imaizumi, A., Fukuda, H., Hashimoto, T., et al. (2011). Innovative preparation of curcumin for improved oral bioavailability. Biol. Pharm. Bull. 34, 660-665. doi: 10.1248/bpb.34.660

Schapira, A. (1999). Science, medicine, and the future: Parkinson's disease. BMJ 318, 311-314. doi: 10.1136/BMJ.318.7179.311

Scheper, W., and Hoozemans, J. (2015). The unfolded protein response in neurodegenerative diseases: a neuropathological perspective. Acta Neuropathol. 130, 315-331. doi: 10.1007/S00401-015-1462-8

Schwarz, D., and Blower, M. (2016). The endoplasmic reticulum: structure, function and response to cellular signaling. Cell. Mol. Life Sci. 73, 79-94. doi: 10.1007/S00018-015-2052-6

Serafini, M. M., Catanzaro, M., Rosini, M., Racchi, M., and Lanni, C. (2017). Curcumin in Alzheimer's disease: Can we think to new strategies and perspectives for this molecule? Pharmacol. Res. 124, 146-155. doi: 10.1016/j. phrs.2017.08.004 
Shah, S. Z. A., Zhao, D., Khan, S. H., and Yang, L. (2015). Unfolded Protein Response Pathways in Neurodegenerative Diseases. J. Mol. Neurosci. 57, 529537. doi: 10.1007/s12031-015-0633-3

Shakeri, A., Zirak, M. R., Wallace Hayes, A., Reiter, R., and Karimi, G. (2019). Curcumin and its analogues protect from endoplasmic reticulum stress: Mechanisms and pathways. Pharmacol. Res. 146:104335. doi: 10.1016/J.PHRS. 2019.104335

Shamsi, T. N., Athar, T., Parveen, R., and Fatima, S. (2017). A review on protein misfolding, aggregation and strategies to prevent related ailments. Int. J. Biol. Macromol. 105, 993-1000. doi: 10.1016/j.ijbiomac.2017.07.116

Sharifi-Rad, J., Rayess, Y., El, Rizk, A. A., Sadaka, C., Zgheib, R., et al. (2020). Turmeric and Its Major Compound Curcumin on Health: Bioactive Effects and Safety Profiles for Food, Pharmaceutical, Biotechnological and Medicinal Applications. Front. Pharmacol. 11:1021. doi: 10.3389/FPHAR.2020.01021

Silvestro, S., Sindona, C., Bramanti, P., and Mazzon, E. (2021). A state of the art of antioxidant properties of curcuminoids in neurodegenerative diseases. Int. J. Mol. Sci. 22, 1-26. doi: 10.3390/ijms22063168

Simeonova, R., Zheleva, D., Valkova, I., Stavrakov, G., Philipova, I., Atanasova, M., et al. (2021). A novel galantamine-curcumin hybrid as a potential multitarget agent against neurodegenerative disorders. Molecules 26:1865. doi: 10 . 3390/molecules26071865

Singh, S., and Aggarwal, B. B. (1995). Activation of transcription factor NF- $\kappa$ B is suppressed by curcumin (diferulolylmethane). J. Biol. Chem. 270, 24995-25000. doi: $10.1074 /$ jbc.270.42.24995

Smith, H., and Mallucci, G. (2016). The unfolded protein response: mechanisms and therapy of neurodegeneration. Brain 139, 2113-2121. doi: 10.1093/BRAIN/ AWW101

Su, I. J., Chang, H. Y., Wang, H. C., and Tsai, K. J. (2020). A curcumin analog exhibits multiple biologic effects on the pathogenesis of Alzheimer's disease and improves behavior, inflammation, and $\beta$-amyloid accumulation in a mouse model. Int. J. Mol. Sci. 21, 1-20. doi: 10.3390/ijms21155459

Tan, K.-L., Ali, A., Du, Y., Fu, H., Jin, H.-X., Chin, T.-M., et al. (2014). Synthesis and evaluation of bisbenzylidenedioxotetrahydrothiopranones as activators of endoplasmic reticulum (ER) stress signaling pathways and apoptotic cell death in acute promyelocytic leukemic cells. J. Med. Chem. 57, 5904-5918. doi: 10. 1021/jm401352a

Tang, M., Taghibiglou, C., and Liu, J. (2017). The Mechanisms of Action of Curcumin in Alzheimer's Disease. J. Alzheimer's Dis. 58, 1003-1016. doi: 10. 3233/JAD- 170188

Taniguchi, M., and Yoshida, H. (2011). Unfolded Protein Response. Compr. Biotechnol. 1, 525-537. doi: 10.1016/B978-0-08-088504-9.00062-3

Taylor, J. P., Hardy, J., and Fischbeck, K. H. (2002). Toxic proteins in neurodegenerative disease. Science 296, 1991-1995. doi: 10.1126/science. 1067122

Tiwari, S. K., Agarwal, S., Seth, B., Yadav, A., Nair, S., Bhatnagar, P., et al. (2014). Curcumin-loaded nanoparticles potently induce adult neurogenesis and reverse cognitive deficits in Alzheimer's disease model via canonical Wnt $/ \beta$-catenin pathway. ACS Nano 8, 76-103. doi: 10.1021/nn405077y

Uehara, T., Nakamura, T., Yao, D., Shi, Z.-Q., Gu, Z., Ma, Y., et al. (2006). S-nitrosylated protein-disulphide isomerase links protein misfolding to neurodegeneration. Nature 441, 513-517. doi: 10.1038/nature04782

Urra, H., and Hetz, C. (2014). A novel ER stress-independent function of the UPR in angiogenesis. Mol. Cell 54, 542-544. doi: 10.1016/J.MOLCEL.2014.05.013

Valera, E., Dargusch, R., Maher, P. A., and Schubert, D. (2013). Modulation of 5-lipoxygenase in proteotoxicity and Alzheimer's disease. J. Neurosci. 33, 10512-10525. doi: 10.1523/JNEUROSCI.5183-12.2013

Vera-Ramirez, L., Pérez-Lopez, P., Varela-Lopez, A., Ramirez-Tortosa, M., Battino, M., and Quiles, J. L. (2013). Curcumin and liver disease. BioFactors 39, 88-100. doi: 10.1002/biof.1057

Voulgaropoulou, S. D., van Amelsvoort, T. A. M. J., Prickaerts, J., and Vingerhoets, C. (2019). The effect of curcumin on cognition in Alzheimer's disease and healthy aging: A systematic review of pre-clinical and clinical studies. Brain Res. 1725, 146476. doi: 10.1016/j.brainres.2019.146476

Wang, H. M., Zhao, Y. X., Zhang, S., Liu, G. D., Kang, W. Y., Tang, H. D., et al. (2010). PPAR $\gamma$ agonist curcumin reduces the amyloid- $\beta$-stimulated inflammatory responses in primary astrocytes. J. Alzheimer's Dis. 20, 11891199. doi: 10.3233/JAD-2010-091336

Wang, M., and Kaufman, R. (2016). Protein misfolding in the endoplasmic reticulum as a conduit to human disease. Nature 529, 326-335. doi: 10.1038/ NATURE17041

Xu, Y. X., Pindolia, K. R., Janakiraman, N., Chapman, R. A., and Gautam, S. C. (1997). Curcumin inhibits IL1 $\alpha$ and TNF $\alpha$ induction of AP- 1 and NF-kB DNAbinding activity in bone marrow stromal cells. Hematopathol. Mol. Hematol. 11, 49-62.

Yang, F., Lim, G. P., Begum, A. N., Ubeda, O. J., Simmons, M. R., Ambegaokar, S. S., et al. (2005). Curcumin inhibits formation of amyloid $\beta$ oligomers and fibrils, binds plaques, and reduces amyloid in vivo. J. Biol. Chem. 280, 5892-5901. doi: 10.1074/jbc.M404751200

Yoon, M. J., Kang, Y. J., Lee, J. A., Kim, I. Y., Kim, M. A., Lee, Y. S., et al. (2014). Stronger proteasomal inhibition and higher CHOP induction are responsible for more effective induction of paraptosis by dimethoxycurcumin than curcumin. Cell Death Dis. 5:e1112. doi: 10.1038/cddis.2014.85

Yu, L.-H., Morimura, T., Numata, Y., Yamamoto, R., Inoue, N., Antalfy, B., et al. (2012). Effect of curcumin in a mouse model of Pelizaeus-Merzbacher disease. Mol. Genet. Metab. 106, 108-114. doi: 10.1016/j.ymgme.2012.02.016

Zhang, C., Browne, A., Child, D., and Tanzi, R. E. (2010). Curcumin decreases amyloid- $\beta$ peptide levels by attenuating the maturation of amyloid- $\beta$ precursor protein. J. Biol. Chem. 285, 28472-28480. doi: 10.1074/jbc.M110.133520

Zhang, X., Zhang, H.-Q., Zhu, G.-H., Wang, Y.-H., Yu, X.-C., Zhu, X.-B., et al. (2012). A novel mono-carbonyl analogue of curcumin induces apoptosis in ovarian carcinoma cells via endoplasmic reticulum stress and reactive oxygen species production. Mol. Med. Rep. 5, 739-744. doi: 10.3892/mmr.20 11.700

Zhao, L., and Ackerman, S. (2006). Endoplasmic reticulum stress in health and disease. Curr. Opin. Cell Biol. 18, 444-452. doi: 10.1016/J.CEB.2006. 06.005

Zheng, A., Li, H., Wang, X., Feng, Z., Xu, J., Cao, K., et al. (2014). Anticancer effect of a curcumin derivative B63: ROS production and mitochondrial dysfunction. Curr. Cancer Drug Targets 14, 156-166. doi: 10. 2174/1568009613666131126115444

Zhongfa, L., Chiu, M., Wang, J., Chen, W., Yen, W., Fan-Havard, P., et al. (2012). Enhancement of curcumin oral absorption and pharmacokinetics of curcuminoids and curcumin metabolites in mice. Cancer Chemother. Pharmacol. 69, 679-689. doi: 10.1007/s00280-011-1749-y

Conflict of Interest: The authors declare that the research was conducted in the absence of any commercial or financial relationships that could be construed as a potential conflict of interest.

Publisher's Note: All claims expressed in this article are solely those of the authors and do not necessarily represent those of their affiliated organizations, or those of the publisher, the editors and the reviewers. Any product that may be evaluated in this article, or claim that may be made by its manufacturer, is not guaranteed or endorsed by the publisher.

Copyright (C) 2021 Mukherjee, Mishra, Peer, Bagabir, Haque, Pandey, Raj, Jain, Pandey and Kar. This is an open-access article distributed under the terms of the Creative Commons Attribution License (CC BY). The use, distribution or reproduction in other forums is permitted, provided the original author(s) and the copyright owner(s) are credited and that the original publication in this journal is cited, in accordance with accepted academic practice. No use, distribution or reproduction is permitted which does not comply with these terms. 